\title{
Aguja dental rota en el espacio pterigomandibular. Reporte de un caso
}

Ghersi H, Martinez A. Aguja dental rota en el espacio pterigomandibular. Reporte de un caso. Rev Estomatol Herediana 2004;14(1-2) : 74 - 77.

\section{RESUMEN}

Los accidentes por fractura de agujas dentales durante la colocación de anestesia, son infrecuentes. Dentro de las zonas más afectadas con esta complicación es el espacio pterigo mandibular, al momento de realizar el bloqueo del nervio alveolar inferior. Los motivos por los cuales se pueden fracturar las agujas son varios, inicialmente se debió al material poco flexible con el que eran construídas, luego que se mejoró la aleación, permitiéndole mayor resistencia, la fractura se debe principalmente a los movimientos bruscos que el paciente realiza al percibir una sensación dolorosa por el ingreso repentino del anestésico, desgarro del periostio, estímulo del nervio lingual o alveolar inferior. También puede ser por defectos en la fabricación de las agujas o pobre técnica del operador. La necesidad del retirar la aguja es controversial, la proncipal razon radica en la presión emocional que ejerce en el paciente, los padres y el propio operador, más que la migración de la aguja en los tejidos. El manejo de estos casos debe ser realizado por un cirujano maxilofacial y se recomienda que sea bajo anestesia general para brindarle mayor comodidad y tranquilidad al paciente, además de tener en cuenta que toda exploración quirúrgica para ubicar un cuerpo extraño es dificil. Se presenta un caso de una niña de 10 años de edad que es referida al servicio de Cirugía Oral y Maxilofacial con antecedente de fractura de aguja dental al momento de la infiltración anestésica del nervio alveolar inferior derecho y de haber sido intervenida en dos ocasiones no lográndose retirar el cuerpo extraño. Se localiza la aguja con la técnica radiográfica de fuego cruzado y se interviene bajo anestesia general, lográndose retirar la aguja. La recuperación fue satisfactoria.

Palabras clave: AGUJAS.

Broken dental needle in the pterigomandibular space. Report of a case ABSTRACT

Accidents due to broken dental needles during anesthesia are infrequent. One of the most affected areas is the pterigomandibular space when blocking the inferior alveolar nerve. There are many reasons for needle fractures being mainly sudden movements of the patient due to painful sensations or poor technique of operator during anesthesia. Also they can happen because of manufacturer defects. The need to withdraw the needle is controversial due to the strong emotional pressure on the patient, the parents and the operator himself, more than the migration of the needle. Handling of these cases must be made by a maxillofacial surgeon under general anesthesia in order to provide reassurance and comfort to the patient considering that every surgical exploration to locate a strange object is difficult. The report of a case of a ten year old girl is presented. She is referred to the maxillofacial and oral surgery service with dental needle fracture during anesthesia of the inferior right alveolar nerve having tried before unsuccessful withdrawal twice. Radiographic localisation of the needle by means of cross fire technique was done and patient is intervened under general anesthesia achieving withdrawal of needle. The recuperation was satisfactory.

Keywords: NEEDLES

\section{Hugo Ghersi Miranda ${ }^{1}$ Alan Martinez López ${ }^{2}$}

Docente del Departamento Académico de Medicina, Cirugia y Patología Oral.

2Alumno del Residentado en Cirugía Oral y Maxilofacial.

Facultad de Estomatología. Universidad Peruana Cayetano Heredia.

\section{Introducción}

La incidencia de rupturas de agujas durante la colocación de anestesia dental ha ido decreciendo significativamente en las últimas décadas. Blum en 1928, observó 100 casos de agujas rotas durante el periodo de 1914 a 1928, de todas ellas, 82 ocurrieron durante la anestesia de los nervios alveolar inferior, lingual y bucal. Fraser-Moodie, en 1958 revisaron 26 casos de fracturas de agujas dentales. Fitzpatrick (1967), en el periodo desde 1950 a 1966, constató 25 casos, de los cuales seis acurrieron en el espacio ptérigomandibular (1,3).

En una revisión de la literatura dental de los últimos 35 años, se encuentran más de 40 publicaciones relacionados con la detección y remoción de agujas rotas. Muller y Lernoud (1967), mencionan que cada vez es menos frecuente las ocurrencias de fracturas de agujas, considerándose que este tipo de accidentes es muy raro en la actualidad $(1-3,5)$.

A pesar que en los sesentas la Asociación Intenacional para la Estandarización estableció las normas para la fabri- cación de las agujas hipodérmicas dentales, con el uso aleación de acero inoxidable flexibles, para el año 2002, todavía se han reportado fracturas de estas agujas $(1-3,5,6)$.

El espacio pterigomaxilar es la zona anatómica donde con frecuencia se pierden las agujas dentales que se rompen, durante el bloqueo del nervio dentario inferior. Las razones de estos accidentes son variadas, dentro de las que se describen fallas de fabricación, estiramiento del metal, movimiento rápido del paciente durante la administración del 
anestésico por diversas razones, inapropiado uso de agujas como insertar por completo la aguja en los tejidos o deflexión de la aguja al mover la jeringa cárpule (2-6).

La actitud a tomar frente a los casoso de agujas rotas dentro de los tejidos es controversial. Es obvio que cuando el paciente presenta síntomas locales, como dolor, disfagia, trismus y posible migración de la aguja será necesario planear su remoción. Se cree que la remoción de una aguja debe hacerse porque el borde cortante puede causar heridas graves. Otra razón es para tranquilizar al paciente $(1,2,4,5)$.

Si el fragmento de aguja está localizado en planos profundos y la exploración quirúrgica puede conducir a daños neurológicos mayores o importante daño tisular, es preferible dejarse la aguja donde se rompió y controlar al paciente periódicamente $(2,3)$. Se acepta que las agujas no migran a grandes distancias a través de los tejidos, y no hay reportes auténticos de la migración de las agujas dentro de estructuras vitales, que hayan causado la muerte $(1,5)$.

Para localizar el fragmento roto es de suma importancia realizar estudios radiográficos minuciosos antes de iniciar la exploración quirúrgica (2). Con este fin se deben utilizar varias incidencias radiográfícas, como radiografías panorámica, lateral estricta, posteroanterior y submento vertex (técnica de Hirtz) (5). Otros procedimientos han sido descritos para la localización exacta de las agujas rotas, tales como detector de metales, ultrasonografía, ondas electromagnéticas, fluoroscopía, técnica estereoestática utilizando el intensificador de imágenes y tomografía axial computada con imagen en 3D (1-3,6,7).

Se presenta un caso de ruptura accidental de una aguja dental a nivel del espacio pterigomandibular, que ocurrió al momento de colocar anestesia para el bloqueo del nervio alveolar inferior.

\section{Reporte de caso}

Una niña de 10 años natural y procedente de Chachapoyas departamento de Amazonas-Perú, acudió al Servicio de Cirugía Oral y Maxilofacial de la
Clínica Estomatológica Central de la Facultad de Estomatología de la Universidad Peruana Cayetano Heredia, refiriendo que hace 25 días durante la infiltración de anestésico al nervio dentario inferior se fracturó la aguja, quedando esta dentro de los tejidos.

El odontólogo trató inmediatamente de retirarla pero no tuvo éxito. Al día siguiente la paciente acudió al Hospital Regional de Chachapoyas, donde le realizan una exploración quirúrgica bajo anestesia general, sin resultados satisfactorios. Es por este motivo, además de la ansiedad mostrada por los padres, que es referida a nuestro servicio para el manejo pertinente.

La paciente no presenta ningún tipo de sintomatología (Fig. 1), sólo una cicatríz en la mucosa a nivel de la zona retromolar derecha, de $0.5 \mathrm{~cm}$ de longitud.

El estudio radiográfico aplicando la técnica de "fuego cruzado” estableció la presencia un fragmento de aguja dental de aproximadamente tres centimetros de longitud ubicada en la región masticatoria profunda, probablemente entre los músculos pterigoideo interno y pterigoideo externo del lado derecho (Fig. 2 y 3).

Con esta información se decide preparar a la paciente para realizar la exploración quirúrgica bajo anetesia general, con el objetivo de retirar la aguja dental fracturada.

Con el paciente bajo anestesia general se infiltró anestesia local a nivel de la cara interna de la rama ascendente derecha, tratando de evitar que se deformen las estructuras anatómicas, luego se realizó una incisión en forma vertical a nivel de la cara interna de la rama ascendente de tres centimetros de longitud. Con un instrumento romo se exploró la zona tomando como referencia las imágenes radiográficas, sin tener éxito. Por tal motivo se procedió a tomar radiografías periapicales en la sala de operaciones, previa colocación de una aguja hipodérmica $\mathrm{N}^{\circ} 21$ en la zona más posterior y superior de lo referido en el informe radiográfico, esto se hizo con la finalidad de obtener un punto de referencia. La nueva imagen radiográfica determinó que la posición de la aguja era más alta, por lo que se procedió a ampliar la incisión hasta el nivel del pilar anterior en su porción superior. Se decoló por planos hasta hallar la porción distal de la aguja que estaba ubicada entre el cuello del cóndilo y el músculo pterigoideo externo. El fragmento de la aguja fue retirado utilizando una pinza hemostática tipo mosquito (Fig 4 y 5). Se realizó hemostasia y cierre por planos con sutura reabsorbible y se indicó antibióticos y analgésicos postoperatorios por cinco días. La recuperación de la paciente transcurrió sin complicaciones.

Una radiografía panorámica de control permitió constatar que el fragmento de aguja fracturado fue retirado (Fig. 6).

\section{Discusión}

Los accidentes por fracturas de las agujas dentales han disminuído dramáticamente con el mejoramiento en los materiales de aleción utilizadas para su fabricación, que permite cierto grado de flexibilidad (2).

La mayoría de odontólogos utilizan agujas $\mathrm{N}^{\circ} 27$ largas y los odontopediatras las $N^{\circ} 27$ a 30 de 20 a 25 mm de longitud para el bloqueo del nervio alveolar inferior. La principal razón es disminuir la sensación dolorosa en el paciente (3).

Muchas veces se piensa que las diferencias de los diámetros de las agujas dentales pueden jugar un rol importante en la causa de dolor al ingresar al tejido, sin embargo los estudios no han encontrado diferencias significativas en la percepción dolorosa, entre las agujas 25, 27 ó 30. Mas bien la presión ejercida para la inoculación de anestesia aumenta a medida que se disminuye el calibre de la aguja, por lo tanto se siente mayores molestias si el diámetro de la aguja disminuye. La velocidad en la colocación del anestésico también influye en la presión de la inyección y la generación de dolor (2).

La fractura de las agujas ocurren con mayor frecuencia durante el bloqueo del nervio alveolar inferior. El incremento de las fracturas de las agujas en el bloqueo de este nervio, se atribuye a la longitud de la aguja (usualmente 35mm), 


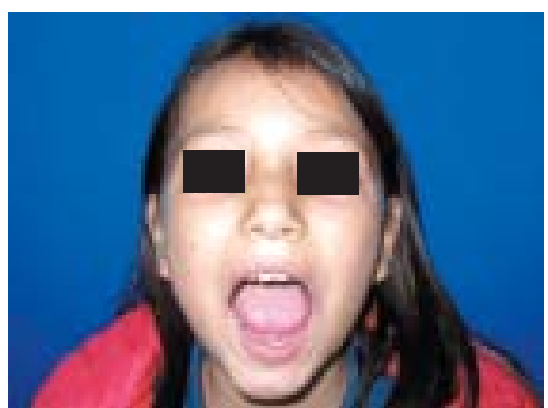

Fig. 1

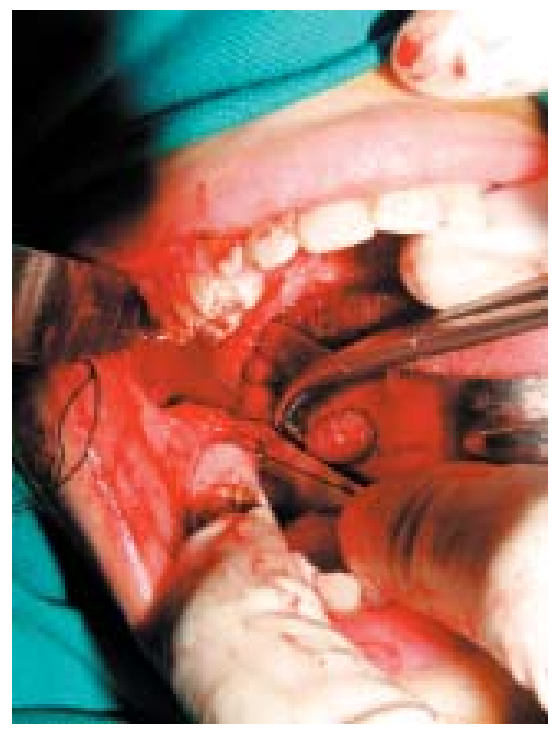

Fig. 4

al filo de la aguja que puede causar dolor cuando estimula directamente en forma accidental el nervio ligual alveolar inferior o el periostio, ocasionando movimientos inesperados de la cabeza que pueden originar la fractura de la aguja dental (2).

Las técnicas para el bloqueo del nervio dentario inferior más utilizados son la directa e indirecta. Se recomienda utilizar el método directo empleando agujas largas de $42 \mathrm{~mm}$ calibre 30 , introduciendo únicamente $2 / 3$ de la longitud de la aguja para que en caso de que ocurra una fractura en la base del adaptador, quede un tercio de la aguja fuera de los tejidos blandos y pueda ser retirada fácilmente. Al utilizar una aguja corta se tiene mayor control, pero se necesita introducir la totalidad de la longitud de la aguja para poder alcanzar el sitio anatómico que se necesita anestesiar, corriendo el riesgo de que si se fracturara la
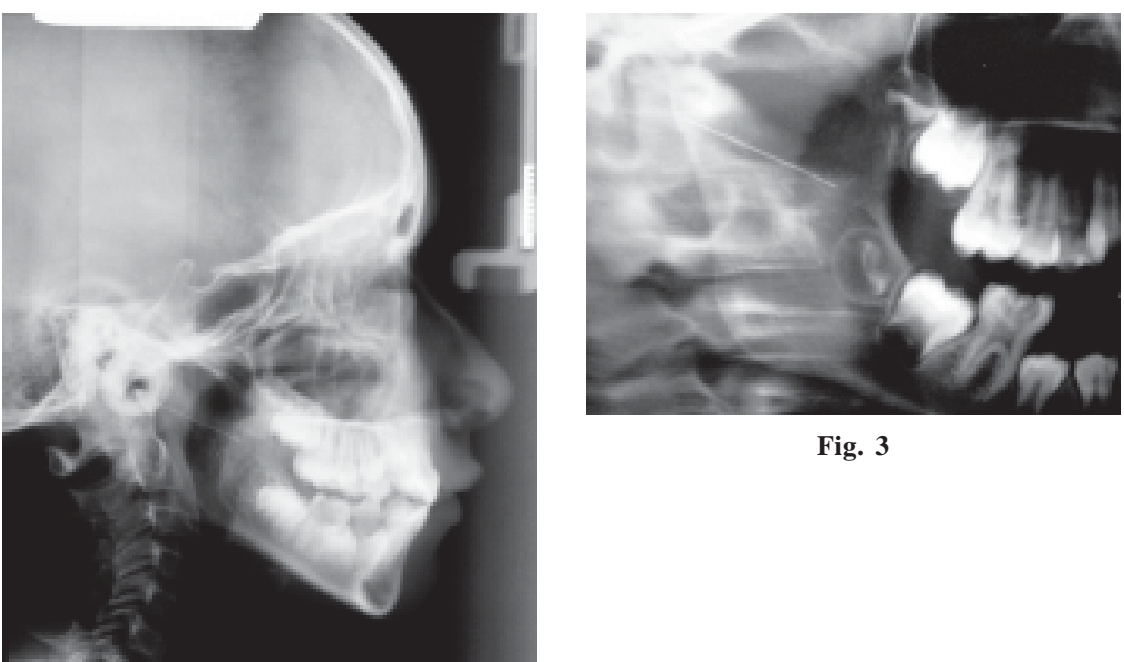

Fig. 3

Fig. 2

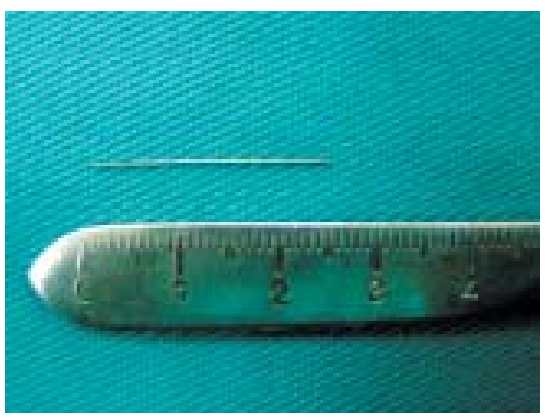

Fig. 5

aguja, la totalidad del fragmento quedará dentro de los tejidos blandos (4).

Muchos autores sugieren la inmediata remoción de la aguja fracturada por varias razones, como son migración de las agujas que pueden producir lesiones a estructuras vitales. La ansiedad originada en el paciente o en los padres de los pacientes es otra de las razones para su retiro $(1,3)$.

Para identificar y ubicar la aguja se pueden utilizar radiografías convencionales, rayos $\mathrm{X}$ guiados, dectores de metales, electromagnetos, fluoroscopía, ultrasonografía, tomografía computarizadas con imagen en 3D y el método estereostático (3).

El conocimiento de la anatomía de la zona, es esencial para el éxito en el retiro de la aguja rota $(3,4)$.

Cuando la aguja es retirada del espacio pterigomandibular, la incisión vertical debe ser hecha medialmente al bor-

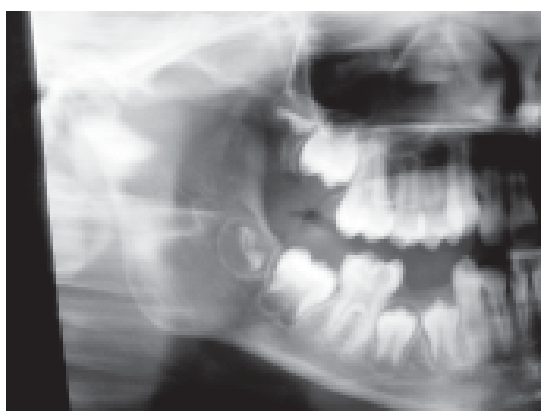

Fig. 6

de anterior de la rama de la mandíbula y la disección medial, posterior y perpendicular a la aguja.

En la paciente de este reporte, no se pudo establecer las razones para la fractura de la aguja. El motivo principal para la remoción fue la ansiedad mostrada por los padres, acentuada por las dos intervenciones previas que tuvo la niña sin éxito. Como se indicó no existía sintomatología ni signos de alteración

El estudio radiográfico para ubicar la aguja se realizó cuatro días antes de de la intervención quiríugica, nosotros consideramos que este estudio debe hacerse inmediatamente previo a la intervención quirúrgica para evitar una imagen distorsionada debido a migraciones.

Con la finalidad de reducir al máximo la probabilidad de fracturas de agujas dentales, sugerimos seguir las sien la paciente. 
guientes pautas:

- El paciente debe tener conocimiento previo a la colocación de la inyección.

- En los paciente pediátricos se debe estar a la espectativa de movimientos intempestivos.

- Utilizar agujas largas N²5 ó N²7 en la anestesia dental.

- NO utilizar aguja menor a calibre N²5 si necesita cambiar la dirección de la aguja dentro de los tejidos.

- Inspeccionar la aguja para detectar alguna irregularidad antes de utilizarla.

- Usar agujas desechables una sola vez.

- Nunca insertar la aguja hasta el adaptador de plástico o metal.

- Nunca doblar la aguja previa a la inyección.

- Evitar la deflección o cambio de la dirección de la aguja mientras se administra la anestesia.

- La colocación del anestésico debe realizarse suavemente.

- Evitar el contacto agresivo con el periostio y los tejido duros.

- Tener una pinza mosquito, dentro del equipo de anestesia dental.

- Apoyar y sostener los tejidos para controlar los posibles movimientos del paciente.

La conducta de emergencia que debe seguir en los casos de ruptura de una aguja son :

- Cuando la punta de la aguja es visible debe retirarse inmediatamente con la ayuda de una pinza hemostática delgada.

- Cuando la aguja no es visible se debe informar al paciente sin alarmarlo e indicandole no realizar movimientos mandibulares bruscos y evitar la manipulación de los tejidos a través de la palpación o la exploración quirúrgica de la región afectada. El paciente debe ser referido tan pronto sea posible al Cirujano Oral y Maxilofacial, quien indicará el estudio radiográfico apropiado y planeará el abordaje quirúrgico pertinente.

La técnica para la remoción de una aguja rota en la región mandibular, debe realizarse siguiendo las siguientes pautas :

La posición del paciente debe permitir una visión clara de los pilares anteriores y la faringe. Para mejorar la visibilidad es mejor utilizar frontoluz y tener un asistente que ayude a retraer $\mathrm{y}$ mantener el campo limpio.

En algunas ocasiones puede ser necesario remover la aguja bajo anestesia general, sobre todo si el paciente presenta trismus, es nervioso o poco colaborador.

No debe palparse los tejidos de la región donde se presume que está localizada la aguja. Es poco probable localizarla digitalmente y mas bien puede forzarse la aguja más profundamente en los tejidos. Realizar el estudio imagenológico pertinente, colocando previamente una aguja, que servirá de referencia en el momento de la cirugía para el abordaje quirúrgico y la disección.

De acuerdo a la imágenes preoperatorias se realiza una nuevo estudio radiográfico intraoperatorio usando como guía otra aguja que se mantiene dentro de los tejidos, luego se realiza la incisión sin penetrar a planos profundos, los bordes de la incisión se retraen y las estructuras son disecadas con cautela utilizando un instrumento romo (1).

Luego de la detección de la aguja se retira con cuidado, se lava profusamente, se realiza la hemostasia y se sutura los tejidos por planos (1).

El presente reporte, pretende llamar la atención sobre los procedimientos dentales que requieren la colocación de anestesia local con la técnica troncular, en donde siempre existirá la posibilidad de la ruptura de la aguja. Accidente que requiere un estudio radiográfico adecuado y minucioso además de la participación del especialista en cirugía oral y maxilofacial.

\section{Referencias bibliográficas}

1. Saad M, Biazolla E, Kanno C, Murayma R, Melo L and Castellini E. Métodos para localizacao de agulhas quebradas durante anestesia intra-bucal. Enfase para o emprego do radioscópio. Revista Regional de Aracatuba A.P.C.D. 2001;22(2):36-41.

2. Marks R, Carlton D, McDonald S. Management of a broken needle in the Pterygomandibular space: report of case. J Am Dent Assoc 1984;109:263-264.

3. Zeltser R, Cohen C, Casap N. The implications of a broken needle in the pterygomandibular espace: clinical guidelines for prevention and retrieval. Pediatric Dent 2002;24(2): 153-156.

4. Hernández F, Véjar I, y Aguirre F. Fractura de aguja dental durante el bloqueo anestésico del nervio dentario inferior. Presentación de un caso clínico. Med Oral 2002;3(IV):88-91.

5. Archer WH. Oral Surgery, 4th ed. Philadelphia:Saunders 1966: 647654.

6. Thompson M, Wright S Cheng LHH, Starr D. Locating broken dental needles. Int J Oral Maxillofac Surg 2003;32:642-644.

7. Burke R. Management of a broken anesthetic injection needle in the maxilla. J Am Dent Assoc 1986; 112(2):209-10.

\section{Dirección de Correspondencia}

Hugo Ghersi Miranda

Av. Honorio Delgado 430. Lima 31 - Perú

381-1950

hghersim@upch.edu.pe 